\title{
ELECCIONES, CONSTITUCIONALISMO Y REVOLUCIÓN EN EL CUSCO, 1809-1815
}

\author{
POR
}

\author{
VÍCTOR PERALTA RUIZ
}

Universitas Nebrissensis. Madrid

Los acontecimientos politicos españoles de 1808 introdujeron en Hispanoamérica prácticas políticas inéditas, que en casos como el de la Audiencia del Cusco se materializaron en la convocatoria periódica de elecciones de representantes a las Cortes, a las Diputaciones Provinciales y a los Ayuntamientos. La pugna de poderes entre el Cabildo, dominado por los constitucionalistas, y la Audiencia, considerada por los absolutistas como máxima instancia del poder, fue interrumpida por el estallido de la revolución liderada por José Angulo el 3 de agosto de 1814, que introdujo un discurso ideológico y unos objetivos políticos ajenos al de los absolutistas y los constitucionalistas, lo que implicó que las elecciones perdieran su significado inicial.

Artículo basado en directa investigación de archivos peruanos y españoles.

La abdicación de Fernando VII, en 1808, provocó en todas las regiones de España la formación de juntas insurreccionales para enfrentar a la invasión francesa. En Hispanoamérica el

SIGLAS UTILIZADAS:

ADC: Archivo Departamental del Cusco.

AGI: Archivo General de Indias, Sevilla.

AHN: Archivo Histórico Nacional, Madrid.

BNL: Biblioteca Nacional, Lima.

CDIP: Colección Documental de la Independencia del Perú, Lima. 
apoyo al levantamiento español propició la irrupción en la política de un público, hasta entonces acostumbrado a desenvolverse dentro de un ámbito privado. Tal cambio fue el resultado de la igualdad política entre españoles y americanos que sancionó el decreto del 22 de enero de 1809, orden que también convocaba las primeras elecciones de diputados a la Junta Central. Tanto la Junta, como el Consejo de Regencia, que se hizo cargo del poder después de disolverse la Junta en enero de 1810 , intentaron encauzar la participación política de los americanos a través de tres tipos de elecciones: de diputados a Cortes Ordinarias, de diputados provinciales y de autoridades municipales.

Las elecciones se desenvolvieron en la mayoría de los virreinatos americanos por senderos distintos al deseado por las autoridades peninsulares. En algunos casos, los procesos electorales incentivaron una participación política entendida como el ejercicio de una soberanía local en la cual sólo debían participar los ciudadanos nativos. Argumentando ese principio, se formaron entre 1809 y 1810 juntas autonomistas en Quito, Chile, Montevideo, Buenos Aires y Caracas. Estas juntas no sólo se mostraron reacias a acatar a las autoridades sino que interrumpieron los procesos electorales a excepción del de autoridades municipales.

En el virreinato del Perú, en contraste con lo que estaba ocurriendo en gran parte de los territorios americanos, la celebración de los tres tipos de elecciones en todos los partidos se dio de modo casi ininterrumpido a lo largo de los seis años del interregno liberal. A pesar de su regularidad, las acusaciones de fraude, los impedimentos de sufragio a ciudadanos hábiles y otros conflictos propios de la mecánica del voto estuvieron a la orden del día en todo el virreinato. Pero en ninguna intendencia adquirió la contienda electoral proporciones tan dramáticas como en el Cusco. Allí, el ritmo de los procesos electorales aumentó, año tras año, el clima de tensión entre ciudadanos identificados con la prédica constitucionalista o con la absolutista.

La furibunda contienda de poderes entre constitucionalistas y absolutistas, luego de que los primeros obtuvieran el control del Cabildo al ganar la primera elección local, fue el antecedente de la sublevación de los hermanos Angulo contra las autoridades españolas el 3 de agosto de 1814. Si bien los absolutistas, 
que controlaban la Audiencia, fueron arrestados por José Angulo, la revolución del Cusco no implicó el triunfo de los constitucionalistas. Esta revolución introdujo una tercera corriente ideológica que buscó rescatar una tradición política de tipo consuetudinario que, a su entender, había sido rota por el absolutismo borbónico y por la modernización política patrocinada por los constitucionalistas. Este encuentro y conflicto entre imaginarios políticos tradicionales y modernos se prolongó hasta marzo de 1815 cuando la revolución del Cusco fue derrotada por las tropas del virrey.

\section{El PODER DE LOS OIDORES}

En la segunda mitad del siglo xviII, los Cabildos continuaron siendo en el virreinato instituciones con poco significado político. De su fuerte presencia local durante el siglo xvi quedaban vagos recuerdos. Su vitalidad se había ido perdiendo durante el siglo XVII al volverse una costumbre la venta de cargos públicos. Con la llegada de la dinastía borbónica, los ayuntamientos experimentaron un declive más vertiginoso, al pasar sus rentas al control directo de la Corona. Desde entonces, los cargos de alcalde y de regidor se incorporaron a los puestos que con carácter honorífico podía adquirir un español o un criollo acaudalados. El Cabildo del Cusco estuvo controlado por el corregidor, que, hasta 1780, presidió todas las esporádicas reuniones de los alcaldes y regidores, además de decidir quiénes podían comprar los cargos.

La supresión de los corregimientos en el virreinato después de la derrota de Tupac Amaru II, la introducción de la intendencia en 1784 y la creación de la Audiencia en 1787 no conllevaron la revitalización del Cabildo cusqueño. La Audiencia y la Intendencia prefirieron ignorarlo. A pesar de que en Lima y otras ciudades, los intendentes hicieron algunos esfuerzos por revitalizar al Cabildo y proveerle de recursos, en el Cusco el intendente Mata Linares fue contrario a delegar poder y renta alguna a una corporación mayormente integrada por criollos, de quienes desconfiaba profundamente (1). Esa fue razón sufi-

(1) John FISHER, Government and Society in Colonial Peru. The Intendant System 1784-1814. Londres, Athlone Press, 1970, pág. 183. 
ciente para oponerse a que la institución municipal administrara alguna renta local. La destitución, en 1785, del regidor Buenaventura Guevara, acusado por Mata Linares de estar implicado en una supuesta abortada conspiración criolla (2), hizo a éste reafirmarse en sus recelos contra el Cabildo.

La convivencia entre la Intendencia y la Audiencia se hizo posible gracias al reparto del espacio urbano cusqueño. Al empezar el siglo xIx, el perfil del poder en la ciudad del Cusco volvió a desequilibrarse al acumular mayor influencia la Audiencia, mientras la Intendencia, por el contrario, entraba en una fase de profundo letargo político. El férreo control burocrático asumido por la Audiencia, redujo a su mínima expresión la participación criolla en los cargos públicos. Se siguió prefiriendo a españoles más que a criollos y mestizos en los empleos. La Audiencia, fortaleció los lazos de dependencia del Cusco hacia Lima contrariando el deseo de los que vieron en su instalación la posibilidad de fomentar el regionalismo (3). El descontento local con la Audiencia se acrecentó en la medida que ésta fue convirtiéndose en baluarte de unas reformas que implicaban la erosión del poder criollo.

El rumor y la delación adquirieron relevancia en el espacio urbano cusqueño como mecanismo de control político de los oidores sobre cualquier tipo de discrepancia a sus medidas. Los hechos que rodearon el descubrimiento de la conspiración de los criollos Aguilar y Ubalde en 1805 confirma la importancia del rumor. La sentencia reconoció que gracias a una delación se evitó que ambos conspiradores apresaran al presidente y los oidores, con lo cual «se hubiera renovado en el centro del Perú la tragedia de Túpac Amaru» (4). El rumor tendría un rol

(2) AGN, Audiencia del Cuzco, 35. «Carta de Mata Linares a José de Gálvez, 15 de octubre de 1785 ».

(3) John FISHER, "Imperialism, Centralism, and Regionalism in Peru, 1776-1845" en Rory MILleR (ed.) Region and Class in Modern Peruvian History. Liverpool, Institute of Latin American Studies, 1987, págs. 26-27.

(4) John FISHER, «Regionalism and Rebellion in Late Colonial Peru: The Aguilar-Ubalde Conspiracy of 1805" en Bibliotheca Americana, vol. I, n. ${ }^{\circ}$ 1, 1982, pág. 53; Nuria SALA, "De Inca a Indígena: Cambio en la Simbología del Sol a principios del siglo XIX" en Allpanchis, n. ${ }^{\circ}$ 35-36. Cusco, Instituto de Pastoral Andina, 1990.

R. I., 1996, n. ${ }^{\circ} 206$ 
fundamental en los acontecimientos derivados de la primera contienda electoral de febrero de 1813.

La Junta Central decidió dar la representación a los americanos, pero en amplia inferioridad numérica frente a los españoles. Al virreinato del Perú le fue concedida una representación. La Junta Central, que en principio reconoció la igualdad entre españoles peninsulares y americanos, terminó en la práctica sancionando la inferioridad política de estos últimos. La orden de elección de representantes fue publicada en la metrópoli el 22 de enero de 1809. Ésta llegó al Cusco cinco meses después de sancionarse y el oidor regente Manuel Pardo, que hacía las funciones de presidente interino de la Audiencia, dispuso la inmediata elección del representante que competiría con los electores de los otros partidos del virreinato por el único puesto de diputado otorgado por la Junta Central al virreinato peruano.

El acto político se realizó en la casa del oidor regente Manuel Pardo y la omnipresencia de la Audiencia cusqueña se confirmó desde un principio, al sortearse como candidatos tres personajes relacionados con la institución: José de Portilla y Gálvez, Manuel Plácido de Berrozábal y el mismo Pardo (5). Portilla y Gálvez había sido regente de la Audiencia entre 1787 y 1791 (6), mientras que Berrozábal era oidor. A esa condición se añade el que todos eran españoles. El control de la Audiencia sobre el resultado electoral estaba garantizado, contando con la anuencia total de los representantes del $\mathrm{Ca}$ bildo. Sólo restaba saber quién de los tres debía ser el representante, para lo cual "inmediatamente se colocaron los nombres de los tres electos en un cántaro, y se ordenó que el señor capitular don Diego Guerrero y yo el representante escribano, saliéramos a traer el primer niño que pase por la calle, que no excediese de edad de ocho años» (7). Los emisarios seleccionaron a Isidro Grande, que introdujo la mano en el cántaro y extrajo la cédula de Manuel Plácido de Berrozábal. La

(5) Vicente Rodríguez Casado y J. A. Calderón Quijano (eds.), Memoria de Gobierno del Virrey Abascal. Sevilla, Escuela de Estudios Hispanoamericanos, 1994, t. I, pág. CXXII.

(6) Carlos Deustua Pimentel, Las Intendencias en el Perú, 1790-1796. Sevilla, Escuela de Estudios Hispanoamericanos, 1965, pág. 175.

(7) AHN, Estado, Leg. 58, F. 
estadía de Berrozábal en Lima fue muy corta y sin éxito, al producirse la elección como diputado del representante limeño José de Silva y Olave.

La tranquilidad de las autoridades peninsulares en el virreinato volvió a interrumpirse al enterarse que la Junta Central había sido disuelta en enero de 1810. El Consejo de Regencia, que se constituyó en reemplazo de la Junta, convocó nuevas elecciones en América. Esta vez los diputados americanos debían juntarse con los representantes españoles en Cádiz para proceder, desde el 24 de septiembre de 1810, a redactar una Constitución. La noticia llegó el 24 de febrero de 1811 y, de inmediato, el virrey la acató aunque puso serios reparos (8). Abascal se mostró muy contrariado con el tono de la convocatoria, viendo en ella una degradación de la autoridad tradicional. La nueva convocatoria electoral a los españoles americanos se hizo con el siguiente tono desusado: «... tened presente que al pronunciar o al escribir el nombre del que ha de venir a representaros en el Congreso Nacional, vuestros destinos ya no dependen ni de los Ministros, ni de los Virreyes, ni de los Gobernadores; están en vuestras manos» (9). La Regencia reconoció la igualdad política entre españoles y americanos, pero ella, como anteriormente lo hizo la Junta, se cuidó de disminuir la representación americana al disponer la elección de un diputado por cada 100.000 habitantes. Para los reinos de España se señaló un representante por cada 50.000 habitantes. Según este mecanismo, el Cusco debía tener un diputado en las Cortes.

En la capital cusqueña los preparativos para la elección del diputado recayeron de nuevo en los oidores, pese a que esta vez las disposiciones otorgaban a los miembros del Cabildo la prerrogativa de organizar el acto. El regente Pardo, con la anuencia de los cabildantes perpetuos, controló la confección de la terna, de la cual debía salir el diputado. La votación se realizó en la sala del Ayuntamiento, en agosto de 1811, concu-

(8) Rubén Vargas Ugarte, Historia del Perú. Emancipación (1809-1825). Buenos Aires, Ed. Huarpas, 1958, págs. 112-113.

(9) BNL, D10309 «Disposiciones del Virrey a la ciudad del Cuzco sobre la formación del padrón de electores y las elecciones en dicho lugar, Lima, diciembre de 1810 ".

R. I., 1996, n. $^{\circ} 206$ 
rriendo los mismos personajes de la elección anterior: el Regente, los dos alcaldes, y los cuatro regidores. En esta ocasión salió electo Manuel Galeano, nombrándolo Pardo, casi de inmediato, oidor honorario (10).

El diputado cusqueño nunca viajó a Cádiz debido a que el Cabildo no le pudo proporcionar los 10.000 pesos destinados a financiar su estadía en la península. En noviembre de 1812, Galeano presentó al Cabildo una última requisitoria, solicitando se resolviera su situación. La corporación municipal acordó negar el estipendio económico solicitado por el diputado, porque "se debe contemplar ya su traslación a España fuera de tiempo y perjudicial a esta capital a mérito de que verificada ésta quedaría ya sin arbitrios para poder aviar el nuevo diputado ordinario que debe elegirse desde luego» (11). Galeano, a pesar de no lograr sus objetivos fue compensado por el regente Pardo, quien patrocinó su candidatura para ser el primer alcalde constitucional.

El 1 de enero de 1812 se realizó en el Cusco la última elección del Cabildo a la usanza antigua. Sólo tres aspirantes, previamente sorteados con anuencia de la Audiencia, pudieron aspirar a ocupar los cargos de alcaldes y regidores. Por el puesto de alcalde de primera elección compitieron Fabián de Rosas, Pedro Regalado y el coronel Miguel Peralta. Fabián de Rosas resultó electo con apenas un voto de diferencia sobre Regalado (12). En la siguiente elección del Cabildo de 1813, los oidores y el intendente se vieron por primera vez ante la imposibilidad de influenciar el desenlace de este tipo de actos políticos.

\section{LOS ORÍGENES DEL CONSTITUCIONALISMO CUSQUEÑO}

Al Ayuntamiento conducido por Fabián de Rosas correspondió dar la bienvenida al nuevo presidente interino de Gobierno,

(10) ADC, Libro de Actas del Antiguo Ilustre Ayuntamiento desde 18 de noviembre del año pasado de 1811 hasta el 14 de febrero de 1812, f. 70.

(11) Horacio Villanueva Urteaga (ed.), Colección Documental de la Independencia del Perú. Conspiraciones y Rebeliones en el Siglo XIX, t. III, vol. 6; Lima, Comisión Nacional del Sesquicentenario de la Independencia del Perú, pág. 13.

(12) ADC, Cabildo, Libro de Actas del Antiguo Ilustre Ayuntamiento del 18 de noviembre del año pasado de 1811 hasta el 14 de febrero de 1812. 
el Brigadier Mateo García Pumacahua, en septiembre de 1812. En un oficio dirigido al virrey, el Cabildo destacó los reconocidos «méritos, fidelidad y amor al Soberano» que rodeaban a Pumacahua. La costumbre de celebrar corridas de toros en honor del gobernador fue postergada tras conocerse la inminente llegada de la Constitución al Cusco, ocasión para la cual se reservaron tales fiestas (13). Pumacahua se desempeñó en el cargo como los anteriores jefes interinos. Sus relaciones con el virrey Abascal y el regente Pardo fueron cordiales y, continuamente, gustaba presidir algunas de las reuniones del Cabildo perpetuo. Pero Pumacahua previno al virrey diciéndole que había notado un ambiente de tensión política en la ciudad. Pumacahua informó a Abascal que algunos abogados habían circulado el rumor de que el virrey estaba dilatando la llegada de la Constitución (14). Pumacahua, en la misma misiva, identificó al abogado Rafael Ramírez de Arellano como el líder de un grupo de revoltosos descontentos con el poder absolutista.

Los temores de Pumacahua no eran infundados. Su autoridad empezó a resquebrajarse el 10 de diciembre de 1812, día de la llegada de la Constitución. La corporación de abogados de la ciudad, donde se congregaban criollos y mestizos, se sintió ofendida por la forma en que Pumacahua, la Audiencia y el Cabildo organizaron las fiestas de la Constitución (15). Los abogados, escribanos, notarios, procuradores y médicos se ofendieron al aparecer en las listas de oferentes de una corrida de toros al lado de los heladeros y los caleros, "oficios que obtienen acaso los más abyectos de la plebe, premeditándose esta determinación y mezcla por el resentimiento concebido contra estos profesores del Foro" (16). Este fue el pretexto del grupo de vecinos para denunciar a todas las autoridades locales como enemigas de la Constitución. A Pumacahua, en concreto, se le acusó de dilatar innecesariamente actividades más importantes como las elecciones del Cabildo y de los diputados a las Cortes ordinarias con el pretexto de las fiestas.

(13) CDIP, t. III, vol. 6, pág. 4.

(14) "Oficio de Pumacahua al Virrey de Lima dirigido el 26 de abril de 1813", Revista Universitaria del Cuzco, n.॰ 10, 1914, pág. 14.

(15) CDIP, t. III, vol. 6, pág. 18.

(16) ADC, Cabildo, Libro Copilador de Oficios, t. 28, caja 7. 
La protesta de los abogados contra la ceremonia oficial de la recepción de la Constitución se materializó en tres memoriales. Todos fueron dirigidos al gobernador-intendente Pumacahua. El del 14 de diciembre hizo pública la aparición de un grupo definido como constitucionalista. Sus treinta y dos firmantes se definieron a sí mismos en términos de ciudadanos que han comprendido «que mejor es obedecer a la ley». Demandaban la supresión de las corridas de toros y las comedias programadas, proponiendo hacer la jura de la Constitución como mandaba el reglamento, es decir, sin ceremonia alguna. Pedían, finalmente, la inmediata celebración de los sufragios populares para nombrar alcaldes y regidores constitucionales. Destacó en este memorial la requisitoria a las autoridades para que se dejase al pueblo "hacer el ejercicio de su autoridad originaria", alusión que parece hacer referencia a una comunidad política de antiguo régimen. Pero, en otro pasaje del documento, aparecen los elementos de una concepción moderna de pueblo como el titular de la soberanía de la nación y principio de toda legitimidad política. En efecto, el memorial asumía que el pueblo, en tanto depositario de la nación, "posee ya una privativa autoridad de transmitir él sólo la jurisdicción ordinaria y económica en los alcaldes y regidores; mira a los actuales en un esqueleto descarnado de todas sus facultades...» (17). Los firmantes del manifiesto lograron suspender las fiestas públicas.

Los autodenominados constitucionalistas resolvieron proseguir su batalla legal contra la arbitrariedad de las autoridades. En un segundo memorial, demandaron que el Cabildo saliente suspendiera la entrega de la fuerte suma de dinero destinada a solventar el pago de los «refrescos celebrantes de la Constitución». Una concepción moderna de la representación política aparece por vez primera en este memorial del 16 de diciembre. En el escrito se asume al Cabildo como la institución representativa del pueblo soberano, definido como el "hermoso retoño de la nueva planta». Los treinta y siete individuos piden, sobre todo, que se supriman las ceremonias que se proyectan realizar y se ahorren los dos mil pesos que ello demandaría al Cabildo $\mathrm{y}$, "si no obstante es despreciada la voz general, la acción legítima y derecho del pueblo, pide éste que se haga la erogación

(17) CDIP, t. III, n.o 8, pág. 194. 
dando los cabildantes fianzas a satisfacción del dueño (el pueblo) que se opone...» (18). Todos garantizan que la salvaguarda de ese dinero permitiría al nuevo Cabildo, constitucionalmente elegido, cubrir los gastos que demandara la presencia del nuevo diputado por el Cusco en las Cortes Ordinarias para «que hable por la nobilísima madre del Perú». Los mismos suscriptores, amparándose en las Constitución, demandaron la celebración inmediata de elecciones de diputados porque «el juntar Cortes cada año, es el único medio legal de asegurar la observancia de la Constitución sin convulsiones, sin desacato a la autoridad y sin recurrir a medidas violentas que son precisas y aun inevitables cuando los males y vicios en la administración llegan a tomar cuerpo y envejecer» (19).

El tercer memorial fue redactado el 23 de diciembre, el mismo día que se juraba la Constitución, y fue firmado sólo por los abogados Rafael Ramírez de Arellano y Manuel de Borja. Ambos atribuyeron la ausencia de la mayoría de los firmantes a amenazas de represalia de las autoridades. Ramírez de Arellano y Borja desafiaron a Pumacahua, amparándose en «el art. 373 de la Constitución que acabamos de jurar solemnemente (y que) faculta a todo individuo para poder reclamar su observancia». En este documento, ambos abogados reclamaron la entrega por el Intendente de los testimonios de acatamiento y ejecución de las garantías económicas, exigidas a los cabildantes empecinados en usar el dinero del Ayuntamiento. Al mismo tiempo, Ramírez de Arellano y Borja rechazaron la "voz esparcida por algunos espíritus depravados que han graduado por subversivo el clamor y voz del pueblo adicto a la Constitución" (20).

Aunque la tercera reclamación nunca fue respondida por el Gobierno, ni el reparto de refrescos se suspendió, el efecto político de las demandas de los constitucionalistas fue amplio y

(18) El segundo memorial publicado como «Petición de '37 individuos' solicitando la vigencia de la Constitución» en Manuel Jesús APARIcio Vega (ed.), Colección Documental de la Independencia del Perú. Conspiraciones y Rebeliones en el Siglo XIX, t. III, vol. 7. Lima, Comisión Nacional de Sesquicentenario de la Independencia del Perú, pág. 4.

(19) CDIP, t. III, vol. 7, pág. 3.

(20) AGI, Lima 1015. «Petición de Rafael Ramírez de Arellano y Manuel Borja para que se jure la Constitución".

R. I., 1996, n.o 206 
notorio. Éste tuvo su resultado más inmediato en el ausentismo de las corporaciones y vecinos el día de la ceremonia oficial de la jura de la Constitución (21). Pumacahua informó al virrey que pese a haberse cursado las invitaciones a las corporaciones y gremios, "ninguno asistió ni concurrió a su celebridad como ordena la Constitución y sólo yo con los Regidores del antiguo Cabildo, con mis subalternos llevé el peso» (22). La Audiencia se sintió muy mortificada con el tono amenazante del tercer memorial, lo que le llevó a sugerir al virrey se abriera un proceso contra los dos abogados firmantes. Ramírez de Arellano fue citado en Lima por las autoridades virreinales para aclarar su conducta. Aprovechando esta coyuntura, el abogado cusqueño hizo imprimir, en enero del siguiente año, una proclama dirigida "a los amigos de la Constitución" (23). En este impreso quedó plasmada la concepción moderna de la idea de nación esbozada en los tres manifiestos del Cusco. Ramírez de Arellano refirió en el escrito que «la Constitución declara que la soberanía reside esencialmente en la nación; que el poder legislativo es probativamente suyo, que el gobierno monárquico moderado no tiene otro objeto que el bien y prosperidad de la patria y sus individuos, que ésta no es hacienda o patrimonio de alguna persona o familia, que todos mutuamente debemos propender a la conservación de esos bienes y derechos que tan íntimamente nos enlazan» (24).

¿Cómo fue posible que un documento que colocaba la voluntad del ciudadano por encima de la autoridad de los funcionarios públicos absolutistas circulara sin censura por el virreinato? La respuesta puede estar en que el abogado cusqueño fue claro en expresar su fidelidad a la Regencia y a las Cortes. Ramírez de Arellano daba la bienvenida a la nueva sociedad que iba a surgir del pleno respecto a la Constitución gaditana, a

(21) «Juramento de la Constitución de 1812», Revista del Archivo Histórico del Cuzco, n.o 3, 1952.

(22) CDIP, t. III, págs. 202-203.

(23) Rafael Ramírez de ARellano, Proclama. Los verdaderos hijos de la nación, son los amigos de la constitución. Lima. Imprenta de los Huérfanos, 1813. La edición constaba de 8 páginas, siendo suscrita en el Cusco el 17 de enero de 1813; ver José ToRIBIo MEdiNA, La Imprenta en Lima, 1584-1824. Santiago, 1907, t. IV, pág. 209.

(24) CDIP, t. III, vol. 7, pág. 25. 
la que llamaba el «libro de la Nación». Asimismo, se reafirmaba en que la "viva voz del pueblo» se encarnaba en las Cortes y festejaba que la Constitución aboliera el Cabildo perpetuo, que pusiera fin a los procesos sin ley en los antiguos tribunales y, por último, que trasladara la soberanía legítima al pueblo mediante el sufragio popular. Por ello, su elogio del sistema representativo no podía ser menor: «el sublime y más palpable ejercicio de la soberanía que se nos comunica de las Cortes como de fuente perpetua, admiramos en nuestros congresos, elecciones y cabildos... nosotros mismos elegimos nuestros padres, formamos nuestros ayuntamientos y atribuimos la jurisdicción a los que han de juzgar» (25). Ramírez de Arellano culminó su reflexión recordando que la institución pública más importante en el Cusco no era la Audiencia sino el Cabildo porque «la policía de salubridad y comodidad, el decoro, la enseñanza pública, los abastos, la industria, la agricultura, el comercio, los establecimientos de beneficencia, y todo lo que al bien común interesa, está encargado a ese ilustre cuerpo que hemos de formar con nuestros votos» (26).

Cuando Ramírez de Arellano retornó al Cusco, la ciudad estaba en plenos preparativos para designar a los electores que, una semana después, debían elegir a los primeros alcaldes y regidores constitucionales. La elección de los electores fue señalada para el 7 de febrero. La irrupción en la política de la población cusqueña se manifestó en la curiosidad que despertaba el contenido de la Constitución y hasta «la plebe ignorante llevaba sus fragmentos escritos por estar escasos los ejemplares y no tener proporción para conseguirlos» (27).

La ciudad fue dividida para la ocasión en diez juntas o distritos electorales, que comprendían a todos los ciudadanos avecindados y residentes en el territorio de una parroquia (ver cuadro I). Según el censo del virrey Gil de Taboada, vivían en el cercado del Cusco, a fines del siglo XviII, unas 33 mil personas (28). Al votar cerca de 900 vecinos, la proporción de cus-

(25) CDIP, t. III, vol. 7, pág. 26.

(26) CDIP, t. III, vol. 7 , págs. $26-27$

(27) CDIP, t. III, vol. 6, pág. 188.

(28) Paul Gootenberg, "Population and Ethnicity in Early Republican Peru: some revisions», Latin American Research Review, vol. 26 (3), 1991, pág. 113.

R. I., 1996, n.o 206 
queños que participaron en este acto político se elevó al 2,7 por 100 de la población total. Las salas consistoriales fueron habilitadas en las principales iglesias de la ciudad. Los vecinos fueron convocados por carteles y bandos públicos para comenzar a emitir su voto en las salas consistoriales desde las nueve de la mañana. Por su mayor número de votantes, la junta parroquial más importante era la Matriz de Españoles convocada en la Iglesia de la Merced. A ella debía concurrir el intendente Pumacahua en calidad de presidente de la Junta Electoral.

CUADRO I

DISTRITO ELECTORAL DEL CUSCO. SUFRAGIO DEL 7 DE FEBRERO DE 1813

\begin{tabular}{|c|c|c|}
\hline Juntas electorales & Votantes & Electores \\
\hline Matriz de Españoles $\ldots \ldots \ldots \ldots$ & 188 & 5 \\
\hline Matriz de Indios $\ldots \ldots \ldots \ldots \ldots$ & 150 & 4 \\
\hline Hospital $\ldots \ldots \ldots \ldots \ldots \ldots \ldots$ & 150 & 4 \\
\hline Belén .... & 75 & 2 \\
\hline San Blas ........... & 75 & 2 \\
\hline San Cristóbal ........ & 37 & 1 \\
\hline Santa Ana ...... & 37 & 1 \\
\hline Santiago ........... & 37 & 1 \\
\hline San Sebastián $\ldots \ldots \ldots \ldots \ldots \ldots$ & 75 & 2 \\
\hline San Gerónimo ............... & 113 & 3 \\
\hline Total & 887 & 25 \\
\hline
\end{tabular}

Fuente: BNL, D8744; CDIP, t. III, vol. 7, págs. 28-32; CDIP, t. III, vol. 8, pág. 149; ADC, Cabildo, Libro de Actas del Cabildo, años de 1813 a 1815.

En vísperas de celebrarse el acto político, varios rumores invadieron la ciudad, corriéndose la voz de que había un plan concertado por los constitucionalistas para «poner un Cabildo a propósito de sus fines» (29). El oidor Pardo fue informado

(29) «Memoria exacta e imparcial de la insurrección que ha experimentado la provincia y capital del Cuzco... por don Manuel Pardo" en CDIP, t. III, vol. 6, pág. 259. 
que en la Iglesia de la Compañía se había hecho circular una lista con los nombres de los constitucionalistas que debían ser electos. La Audiencia decidió tomar cartas en el asunto. Pumacahua, por sugerencia de los oidores Pardo y Cernadas, ordenó el arresto de Ramírez de Arellano y de Borja en vísperas del inicio del sufragio por considerar que ellos eran los líderes del complot. Entre tanto, la Audiencia aceleró los preparativos para que sus adeptos lograran copar las listas de electores y así conformar un Cabildo a su gusto. Pero el desarrollo de los acontecimientos en el sufragio que se realizaba en la Iglesia de La Merced, sede de la Matriz de Españoles, cambió el rumbo de la elección.

En el patio de la Iglesia, Pumacahua se disponía a iniciar el proceso electoral emitiendo su voto, cuando se vio interrumpido por gritos de los asistentes que pedían la libertad de Ramírez de Arellano y Borja. Los ánimos se caldearon más cuando los vecinos se negaron a emitir su voto en tanto no se produjera la liberación de ambos abogados. Pumacahua, reacio a soltar a quienes acusaba de enemigos de la «fe, el Rey la patria", se vio precisado a acceder no sin antes solicitar una fianza escrita que, "a nombre del pueblo", firmaron los vecinos Domingo Rozas, Martín Valer y Juan José Olañeta (30). La decisión de Pumacahua, produjo la primera movilización popular en favor de los constitucionalistas. Una multitud enrumbó hacia el cuartel donde estaban confinados Ramírez de Arellano y Borja, "toda aquella gente decía a voces y demostración de alegría: viva la Constitución y salgan los presos que hace más de veinte y cuatro horas no se les ha tomado confesión" (31). Ambos abogados luego de ser liberados pudieron participar en la elección.

El sufragio culminó a las nueve de la noche en medio de sorpresas. En la Matriz de Españoles triunfaron los constitucionalistas, al obtener cuatro de los cinco electores. Estos fueron el Teniente Pedro López de Segovia, el Teniente Coronel de Milicias Martín Valer, el Tesorero Baltazar Villalonga y el abogado

(30) «Información producida en el juzgado del Señor Alcalde de Primer Voto por los cinco electores de la Matriz, sobre lo ocurrido en la Junta Parroquial del día 7 de febrero de 1813 » en cdip, t. III, vol. 6, pág. 162.

(31) CDIP, t. III, vol. 6, pág. 152. 
Manuel Borja. En el resto de las juntas parroquiales la jornada transcurrió sin alteración alguna. En varias parroquias triunfaron los adeptos del oidor Pardo, lo que presagiaba una difícil disputa para el siguiente domingo en que debían elegirse los dos alcaldes, doce regidores y dos procuradores síndicos del Cabildo constitucional. El oidor honorario y ex-diputado Manuel Galeano, favorito de la Audiencia, compitió con el Teniente Coronel Martín Valer, candidato de los constitucionalistas, para alcalde de primer voto. Los veinticinco electores luego de reunirse en la Sala del Ayuntamiento y escuchar con Pumacahua un sermón religioso procedieron a iniciar el acto político. Manuel Galeano obtuvo doce votos, mientras Martín Valer logró once, recayendo uno en Mariano Arechaga y otro en Cayetano Ocampo. Al no obtener Galeano la mayoría requerida para ser alcalde, la mesa dispuso una nueva elección entre los dos más votados. La elección final favoreció a Valer que obtuvo trece votos, conservando Manuel Galeano sus doce votos originales. El triunfo de los constitucionalistas se reafirmó al recaer en ellos la alcaldía de segundo voto, la mayoría de los cargos de regidores y la de los dos procuradores síndicos. Ramírez de Arellano obtuvo el puesto clave de primer procurador síndico, al triunfar con trece votos sobre el candidato oficialista Miguel Vargas que obtuvo once. Otro líder clave del constitucionalismo, el abogado Francisco Sotomayor y Galdós, fue elegido segundo procurador síndico. Al asumir funciones el 1 de enero de 1813, la corporación municipal devino en el soporte institucional de los constitucionalistas cusqueños.

\section{El CABILdo EN PUgNa POR EL PODER}

Las disputas por las jurisdicciones administrativas locales entre el Cabildo Constitucional recién formado, el Presidente Interino y la Audiencia estallaron con el nuevo año. Fue el procurador síndico Sotomayor y Galdós, en un proyecto político elevado al Cabildo el 25 de febrero, quien puso en claro las aspiraciones de los constitucionalistas. Sotomayor ideó un plan mediante el cual debía corresponder a la Diputación Provincial, al Ayuntamiento y al Colegio de Abogados, el futuro 
gobierno interior de la ciudad (32). En dicho proyecto, tanto la Audiencia como la Iglesia debían quedar sujetos a la jurisdicción de esas tres corporaciones. En el mismo documento se proponía que los curas estuvieran obligados a concurrir periódicamente a dar un examen sinodal de sus obligaciones. En el apartado acerca de los tribunales reales, Sotomayor pensó que todo magistrado de la Audiencia debía ser examinado a los tres años de la posesión de su empleo «por los individuos que elijan a pluralidad de votos la Diputación Provincial, el Ayuntamiento de la ciudad y el Colegio de Abogados» (33). Todo el plan apuntaba a que quedaran en manos de los ayuntamientos y diputaciones provinciales el control de las rentas e industrias además del orden público de la ciudad. Enterados del plan, los oidores decidieron distintas estrategias para frenar el proyecto de los cabildantes.

En su intención de debilitar al Cabildo, tanto el Gobernador Intendente Pumacahua como la Audiencia pusieron en práctica distintas estrategias. Pumacahua apeló a la fuerza pública para amedrentar a «la parte de la plebe movida a la devoción de tales sujetos» (34). Para el presidente interino, la multitud movilizada desde el día de las elecciones por los constitucionalistas, era una banda compuesta por ebrios, ladrones y saqueadores de la ciudad. Pumacahua opinó que el control de la plebe sólo podría hacerse apelando al Regimiento de los Nobles Indígenas de la ciudad. Enterado el Ayuntamiento por un rumor que $\mathrm{Pu}-$ macahua "había resuelto convocar diversas partidas de indios de las parroquias de esta capital que componían el número de cerca de dos mil» (35), citaron al gobernador a la corporación para aclarar los hechos. Pumacahua ocultó su verdadera intención diciendo que su único motivo había sido capturar a unos ladrones fugados de la cárcel. En las semanas siguientes, las re-

(32) "Copia de un Proyecto Político en orden a varios particulares de la provincia del Cusco» en CDIP, t. III, vol. 7, pág. 15. Ver también John FisHeR, "Royalism, Regionalism and Rebellion in Colonial Peru, 1808-1815», Hispanic American Historical Review, vol. 59, n. 2, 1979, pág. 249.

(33) CDIP, t. III, vol. 7, pág. 15.

(34) CDIP, t. III, vol. 6, pág. 204.

(35) ADC, Cabildo, Libro de Actas del Cabildo del Cuzco, años de 1813 a 1815. Acuerdo del 1 de marzo de 1813.

R. I., 1996, n. $^{\circ} 206$ 
laciones entre el Cabildo y el gobernador no hicieron más que empeorar.

El 24 de abril el procurador síndico Ramírez de Arellano vetó el nombramiento hecho por Pumacahua del abogado Norberto Torres como juez de letras, "por no ser adicto a la constitución» (36). Pumacahua fue acusado por Ramírez de Arellano de impartir órdenes sin tomar en cuenta que sólo era una autoridad accidental y que la verdadera lo era el Cabildo. El Ayuntamiento, semanas después, se encargó de calificar a Pumacahua como un personaje "bondadoso, pero inepto» (37). La tensión no se prolongó mucho tiempo. En un oficio dirigido al virrey Abascal el 26 de abril de 1813, Pumacahua renunció al cargo de intendente "ya (que) se dice en este pueblo que Vuesencia con disimulado pretexto me ha quitado el gobierno, que para mí ha sido de sumo gozo, pues me liberto de asechanzas de tantos hombres...» (38). El abandono del puesto la efectivizó el mismo Pumacahua a principios de mayo, siendo de inmediato censurado por el Cabildo por su «escandaloso abandono» (39).

Mientras Pumacahua sucumbía a las presiones del Cabildo, la Audiencia prefirió enfrentar a la corporación usando la presión legal. Se trataba de recordar al Cabildo su sometimiento a la jurisdicción política del máximo tribunal. El regente Pardo recordó a los cabildantes la vigencia de un decreto «en el que les advertía que la dignidad de ciudadano, no excluía el respeto debido a las autoridades legítimas» (40). La Audiencia prohibió a los cabildantes el uso de vestimentas similares a las usadas por los oidores en las celebraciones públicas. Seguidamente, reabrió el proceso judicial contra el procurador Ramírez de Arellano, por intentar remover al relator de sala y doméstico del oidor Vidaurre (41). En todos estos casos, se advirtió al Cabildo de abstenerse de invadir la esfera política que era el ám-

(36) «Reparos hechos por el Dr. Rafael Ramírez de Arellano a Mateo Pumacahua...» CDIP, t. III, vol. 7, pág. 57.

(37) CDIP, t. III, vol. 7, pág. 41.

(38) CDIP, t. III, vol. 6, pág. 204.

(39) ADC, Cabildo, Libro de Actas del Cabildo del Cuzo, años de 1813 a 1815. Sesión del 5 de mayo de 1813.

(40) CDIP, t. II, vol. 7, pág. 100.

(41) «La Audiencia del Curso informa sobre los desacatos del doctor Rafael Ramírez de Arellano...» CDIP, t. III, vol. 7, pág. 99. 
bito de la Audiencia (42). Por su parte, el Cabildo contraatacó acusando a los oidores Pardo, Bedoya, Cernadas y Vidaurre de arrogantes y resentidos. La fortaleza de la Audiencia sobre el Cabildo quedó remarcada al resultar elegidos todos sus candidatos en las elecciones de diputados provinciales y de diputados a Cortes Ordinarios de 1813-1814 realizadas en el transcurso del año. Pero los constitucionalistas estaban sólo interesados en consolidar su dominio del espacio urbano de la capital. No obstante, éstos buscaron ganarse las simpatías de los diputados provinciales. La oración política de saludo a la Diputación Provincial correspondió al catedrático de San Bernardo, Carlos Jara, conspicuo constitucionalista. Jara demandó a los nuevos diputados a no sucumbir frente al peligro que representaba el empeño de ciertas autoridades locales de confundir la tranquilidad con la indiferencia política: «el nuevo orden de cosas, es preciso confesarlo, ha encontrado innumerables contradicciones... esa indiferencia por el bien público, que se nos inspiraba como el estado de la tranquilidad pública: la ignorancia y aún la estupidez, han combatido y van combatiendo a la Constitución bajo mil formas diferentes» (43).

A principios de octubre de 1813 la Audiencia, atendiendo un nuevo rumor, ordenó el arresto de los militares Vicente Angulo, Gabriel Béjar y Juan Carbajal, acusándolos de haber planeado una conspiración para derribar al gobierno local. La tensión política se extendió el mismo día a toda la capital, multiplicándose las patrullas y rondas nocturnas, asistidas por los oidores Pardo y Bedoya en busca de más sospechosos (44). El malestar de la población con la Audiencia se acrecentó y, contra su deseo, hizo que aumentaran las simpatías por el Cabildo y los constitucionalistas. El 5 de noviembre, la capital fue de nuevo invadida por una serie de rumores que aceleraron la descomposición del orden sostenido por la Audiencia. Ese día, los oidores fueron advertidos que un grupo de conspiradores tramaba la toma del cuartel para rescatar a los tres

(42) «La Audiencia del Cusco informa a la Regencia del reino sobre la conducta del Cabildo Constitucional del Cusco y sobre su síndico Rafael Ramírez de Arellano», CDIP, t. III, vol. 7, pág. 114.

(43) El Peruano Liberal, n.o 7, Lima, 21 de octubre de 1813.

(44) CDIP, t. III, vol. 6, pág. 260. 
militares apresados. La delación volvió a surtir efecto. Pardo ordenó al intendente Martín de Concha que alertara a la guardia nocturna, prohibiéndose la circulación por las zonas aledañas al centro de la ciudad. La medida provocó la indignación de algunos ciudadanos, quienes protestaron e intentaron sobrepasar a los piquetes armados. El saldo de la refriega fue de tres muertos.

Resulta importante reseñar las distintas versiones que la Audiencia, el Intendente y el Cabildo hicieron de los hechos. El Cabildo, a los dos días, pidió explicaciones al intendente Martín de la Concha, calificando el uso de la fuerza como una transgresión de la ley y un ataque al «honor del pueblo» y del «inocente Cusco». Definió el hecho como una infracción grave de la constitución por "estar encargada la conservación y quietud común a esta Ilustre Corporación, según el artículo 321, por residir en ella y su presidente el Gobierno interior del pueblo, por el artículo 309, cuanto por los citados señores ministros no tienen ni pueden tener... conocimiento alguno sobre los asuntos gubernativos y económicos de sus provincias, ni comisión, ni otra ocupación que la del despacho de los negocios de su Tribunal»(45). El intendente Concha justificó la violencia de la guardia nocturna en un intento de controlar a «algunos díscolos que tramaban apoderarse del cuartel». El gobernador, en clara advertencia al Cabildo, añadió que cualquier censura a su autoridad «deberá numerarse o en la clase de sedicioso o en la de amate del desorden» (46). El informe elevado por la Audiencia al virrey el 11 de diciembre fue claro en calificar el hecho como una provocación del pueblo contra la autoridad. Los oidores justificaron la utilización de la fuerza como único modo de cortar la intención de los conspiradores de poner las armas en manos del «populacho". Pardo calificó a todos aquellos que concurrieron a la plaza la noche del 5 de noviembre de «malvados hombres, ingratos a su patrio suelo... desconocidos a la lenidad y suavidad con que se les trata, todos quebrados y de baja extracción y escasa suerte, (que) poseídos con certeza de que nuestras armas del Alto Perú iban a ser arrolladas y venci-

(45) ADC, Cabildo. Libro de Actas del Cabildo del Cusco para los años de 1813 y 1815 . Sesión del 7 de noviembre de 1813 .

(46) CDIP, t. III, vol. 6, pág. 40. 
das por las de los insurgentes porteños, habían difundido y regado estas especies especialmente entre la ínfima plebe, de fácil creencia en todo" (47).

El uso positivo que del término "pueblo" hicieron los constitucionalistas en contraposición al uso peyorativo del mismo por la Audiencia y la Intendencia, fue vital en el aumento de la popularidad de los cabildantes en la capital. En esa guerra de palabras, los cabildantes obtuvieron un resonante triunfo al obtener la simpatía y apoyo de numerosos vecinos. El Cabildo logró un golpe de efecto en su empeño de ampliar su base social al disponer "vindicar el fidelísimo amor y respeto que la ciudad ha siempre tributado al soberano y a quienes le representan», declarando mártires de la patria a los tres muertos en la refriega del 4 de noviembre (48). El acto político que puso a prueba la popularidad alcanzada por los constitucionalistas a fines de 1813 fue la segunda elección popular de alcaldes y regidores. Las juntas electorales de parroquia para la elección del segundo Cabildo constitucional se celebraron el 5 de diciembre de 1813. El sufragio en las diez parroquias de la capital transcurrió en un ambiente de tranquilidad. En el recuento final de la votación el número de electores abogados y párrocos predominó en todas las mesas parroquiales. En seguida, Ramírez de Arellano, nombrado elector por la parroquia del Hospital, fue el encargado de preparar la lista de los candidatos «constitucionales» a elegirse el 19 de diciembre. Los resultados del sufragio condujeron al triunfo constitucionalista. A diferencia de la elección de febrero, éstos no tuvieron oponente alguno de parte de los absolutistas. Como alcalde de primera elección fue electo el Coronel Pablo Astete con la totalidad de los votos. El segundo Cabildo constitucional entró en funciones el 1 de enero de 1814.

Una semana después de producirse el relevo de las autoridades municipales, la Audiencia hizo llegar a los ex-cabildantes Valer, Ramírez de Arellano y Francisco Sotomayor un citatorio judicial donde se les daba seis días de plazo para comparecer

(47) «La Audiencia del Cusco informa sobre los movimientos revolucionarios intentados en esa ciudad en octubre y noviembre de 1813", CDIP, t. III, vol. 7, págs. 165-166.

(48) CDIP, t. III, vol. 6, pág. 261.

R. I., 1996, n.o 206 
en Lima. En la requisitoria fue incluido el agente fiscal Agustín Ampuero en calidad de cómplice. A los cuatro se les abrió juicio por desacato a la autoridad local y por alteración de la tranquilidad pública. Ramírez de Arellano puso serios reparos a la requisitoria ya que, en su opinión, la Constitución sólo contemplaba juicios de residencia a los ex-funcionarios. Todos aceptaron marchar a Lima a asumir su defensa. Para fundamentarla, los cuatro acusados obtuvieron un informe del Ayuntamiento acerca de su actuación política. Dicho informe luego de resaltar el apego a la ley de los cuatro, destacó sus esfuerzos para evitar el caos político en la capital. El informe concluyó calificando a los cuatro de artífices de «la incomparable fidelidad, subordinación, carácter y entusiasmo con que ha observado y conserva esta ciudad su tranquilidad interior y de las provincias que no han padecido el contagio de los disidentes del Río de la Plata» (49).

El segundo Cabildo constitucional se avocó a desmontar algunos símbolos del absolutismo en la ciudad, poniendo en práctica una orden de la Regencia que mandaba a los ayuntamientos quitar y demoler todos los signos de vasallaje en sus entradas y casas capitulares. La corporación se suscribió a la colección de sesiones de las Cortes (50), para estar al tanto de los acontecimientos en la península. Las relaciones entre el Cabildo y la Audiencia volvieron a tornarse tirantes, luego que la corporación municipal presentara al virrey su versión de los sucesos de noviembre. La corporación municipal tuvo el cuidado de afirmar que la fuerza pública produjo «el silbido e ignorante algazara de la plebe» (51). Es probable que al omitir el Cabildo el uso de la palabra pueblo, y preferir el de plebe, buscara exonerar a los constitucionalistas de cualquier participación en los hechos del 4 de noviembre. El enojo que el informe produjo en Manuel Pardo no tardó en expresarse en una misiva, dirigida a los miembros del Cabildo, en el que les conminaba a no entrometerse en los asuntos políticos.

(49) «Informe del Ayuntamiento» en CDIP, t. III, pág. 198.

(50) ADC, Cabildo. Libro de Actas del Cabildo del Cusco, para los años de 1813-1815. Sesión del 14 de enero de 1814.

(51) «Informe del Ayuntamiento Constitucional del Cusco sobre los acontecimientos de la noche del 5 de noviembre último", CDIP, t. III, vol. 7, pág. 291. 
No todo fue armonía en el nuevo Cabildo constitucional, la relación entre sus miembros no atravesaba por buenos momentos. El alcalde de primer voto no sólo no juró el cargo sino que, por razones que se desconoce, permanentemente se negó a asumir esa responsabilidad. Formalmente, el Coronel Pablo Astete presentó su renuncia en junio (52), creando una situación inédita de interinaje en el cargo. Hasta junio las sesiones de la corporación fueron presididas por el alcalde de segunda elección, Juan Corbacho, y desde el momento de saberse la decisión de Astete, asumió de alcalde interino Mariano Lechuga, el regidor decano. Mientras la ausencia del alcalde creaba una crisis de representación en el Ayuntamiento, el intendente Martín de la Concha convocó la tercera elección para nominar a los tres representantes del Cusco a las Cortes Ordinarias de 1815-1816. No se tiene información alguna sobre los resultados del sufragio de compromisarios y electores de parroquias. Se sabe que los treinta electores nominados se reunieron el segundo domingo de febrero para elegir al único elector del partido. El resultado fue la elección de Domingo de Echave y Mollinedo, cura de la parroquia de San Sebastián. Echave y los otros nueve electores de provincia fueron citados en la sala consistorial del Ayuntamiento de la capital cusqueña el 22 de marzo. La Junta Electoral provincial la componían dos curas, dos subdelegados y seis militares. Como en la elección del año anterior para diputados a cortes, los constitucionalistas brillaron por su ausencia. Los electores eligieron a viva voz al mariscal de campo Francisco de Picoaga y a los curas Miguel de Orosco y Juan Munive y Mozo (53). Este último era, asimismo, diputado provincial. Los resultados complacieron al gobernador intendente. Sin embargo, ninguno de los tres llegaría a embarcarse a Cádiz. La revolución que estallaría en agosto de 1814, pondría a estos representantes en diferentes bandos y circunstancias.

(52) ADC. Cabildo. Libro de Actas del Cabildo del Cusco, años 1813 a 1815. Sesión del 15 de junio de 1814.

(53) «Poder de los Señores Electores del Partido por la Provincia del Cusco» CDIP, t. III, vol. 7, págs. 288-289.

R. I., 1996, n.o 206 


\section{LA REVOLUCIÓN DE 1814 Y LA AGONÍA DEL CONSTITUCIONALISMO}

El Cabildo fue sorprendido por los acontecimientos que precipitaron la revolución del 3 de agosto de 1814. La revolución principió cuando un grupo de doscientos rebeldes liderados por José Angulo asaltó el cuartel donde estaban confinados los militares arrestados en noviembre de 1813. Los cabildantes, al temer una nueva acción represiva por parte de la Audiencia, sólo atinaron a emitir un bando censurando el uso de la fuerza pública en contra la población. José Angulo, luego de consolidar su control sobre el cuartel, concurrió al Cabildo y explicó haberse sublevado contra la tiranía de las autoridades y su falta de respeto a la constitución. En ese momento los cabildantes se enteraron del apresamiento del intendente Martín de la Concha y de los oidores Pardo, Bedoya, Cernadas y Subiaga. La corporación municipal, sin salir de su asombro, recibió la propuesta de Angulo de plegarse al movimiento y colaborar en la nominación de una junta protectora de gobierno integrada por cinco individuos (54). Angulo sugirió cuatro nombres, el del oidor Manuel Vidaurre y los ex-cabildantes Martín Valer, Luis Astete y Miguel Peralta.

Mientras tanto, el Cabildo aceptó la propuesta de aportar un miembro a la junta. Superando su desconcierto inicial, los cabildantes sugirieron a Angulo el nombre del mariscal Francisco Picoaga. Pero Picoaga fue vetado por Angulo, asegurando que «no era de la satisfacción del pueblo». Angulo propuso al secretario municipal Pedro Miguel de Urbina por «su probada defensa de la constitución», pero Urbina declinó. Finalmente, ambas partes acordaron colocar en el cargo al abogado Toribio Salas. Angulo se retiró de la sesión, ordenando a la corporación que se oficiara el nombramiento sin demora. Horas más tarde Salas se negó a formar parte de la junta. Angulo volvió a dirigirse al Cabildo proponiendo al abogado Jacinto Ferrándiz para sustituir al renunciante. El Cabildo se negó a secundar tal propuesta aseverando que "ni las leyes ni atribuciones de este Ayuntamiento, le facultan para hacer nombramientos de autoridad alguna, de suerte que si esta mañana convino con propo-

(54) ADC, Cabildo. Libro de Actas del Cabildo, años de 1813 a 1815. Sesión del 3 de agosto de 1814 .

R. I., 1996, n.o 206 
ner a don Toribio Salas para que reunido con los nombrados por VSS tratase de la conservación del buen orden, tranquilidad y seguridad del ciudadano, fue porque no aspira ni puede aspirar a otra cosa; pero supuesto que a consecuencia de la renuncia han nombrado VSS por decreto de esta fecha a don Jacinto Ferrándiz, nada tiene que exponer esta corporación» (55).

La historia de la formación de la primera junta revolucionaria, luego de saberse que el Cabildo no iba a participar en ella, es bastante conocida. Del grupo originalmente propuesto, sólo el coronel Luis Astete aceptó el cargo. Astete, Jacinto Ferrándiz y Juan Tomás Moscoso integraron la junta inicial. Luego $\mathrm{Fe}$ rrándiz renunció, posibilitando la incorporación al gobierno del ex-intendente Mateo García Pumacahua, llamado al movimiento por su influencia sobre la población indígena. Angulo tuvo cuidado en reservarse para sí y su hermano Vicente el control de la Comandancia General del departamento (56).

La reacción de Angulo a la negativa del Cabildo de dar su apoyo a la junta fue trasladar a la Diputación Provincial la misma oferta que los cabildantes se habían negado a asumir. La corporación provincial sí reconoció al nuevo gobierno. Similar postura fue tomada por el Cabildo eclesiástico, en contra de la opinión de algunas órdenes religiosas, como los bethlemitas, que prefirieron salir de la ciudad. Los constitucionalistas, entre tanto, acordaron mantener un' contacto prudencial con los revolucionarios, sin que ello implicara colaboración alguna. Fue el regidor Valer quien negó a Angulo la posibilidad de que su padre, el ex-alcalde Martín Valer, pudiera integrar la junta provisional debido a su avanzada edad. Más tarde, uno de los regi-

(55) ADC, Cabildo. Libro de Actas del Cabildo del Cusco, años de 1813 a 1815. Sesión del 3 de agosto de 1814. La postura del Cabildo, según sus propias actas, contradice lo aseverado por Heraclio Bonilla acerca del incondicional apoyo de esta Corporación a la Revolución, ver Heraclio Bonilla et al. La Independencia del Perú. Lima, 1981, pág. 45.

(56) Entre los análisis que se han realizado sobre la revolución del Cuzco, continua siendo importante el estudio de Manuel Aparicio Vega, El Clero Patriota en la Revolución de 1814. Cusco, 1974. También, John FISHER [32], págs. 252-257 y [3], págs. 26-29. Una buena síntesis sobre la proyección rural del movimiento en David CAHILl y Scarlett O?PHELAN «Forging their Own History: Indian Insurgency in the Southern Peruvian Sierra, 1815" en Bulletin of Latin American Research, vol. II, n. ${ }^{\circ}$ 2, 1992, págs. 140-161.

R. I., 1996, n.o 206 
dores, Marcos Martínez, prefirió huir de la capital antes que verse inmiscuido en los hechos.

Otra táctica del Cabildo para desvincularse de los revolucionarios fue intensificar la comunicación con el virrey Abascal. En una de sus misivas, el Cabildo manifestó al Virrey que era de destacar «la tranquilidad en que se mantenía el pueblo cortados los desórdenes en lo posible por los desvelos e intereses con que se ha conducido este ilustre Ayuntamiento" (57). La tarea del Cabildo no sólo se encaminó a defender el espacio urbano ganado desde 1813, sino también a evitar la ruptura del Cusco con Lima. Los cabildantes optaron por hacer oposición al gobierno provisional de Angulo vetando, por ejemplo, el nombramiento del sacristán de la capilla de Santa Bárbara. El Ayuntamiento en su intención de salvaguardar el fidelismo se dirigió a la Comandancia General, exigiendo protección para sus hasta entonces contrincantes políticos: los oidores encarcelados.

Los objetivos del proyecto político de Angulo eran radicalmente contrarios a los del grupo constitucionalista. El 16 de agosto, Angulo hizo circular un manifiesto a los habitantes del Cusco, donde precisó que su proyecto acudía al rescate de una antigua libertad -el pilar del derecho natural- cortada por la presencia tiránica de las autoridades españolas. En la búsqueda de ese objetivo, Angulo justificó la ruptura con la metrópoli como un designio de las leyes divinas. Precisó que si bien la ley natural permitía la renuncia a la independencia, en cambio, no justificaba la pérdida de la libertad. A su modo de ver, con la instauración en el transcurso del absolutismo, la ilustración y el imperio de la razón, aquella libertad terminó socavándose. Angulo demandaba la restitución de la soberanía no delegable de una tradición antigua rota desde las reformas borbónicas, donde resultaba «menos mal estar expuesto a la voracidad de las fieras de que uno puede precaverse, y a las pasiones de nuestros semejantes que están aisladas, que al despotismo razonado» (58). Este tipo de pensamiento tampoco podría coincidir con el de los «modernos» constitucionalistas,

(57) ADC, Cabildo. Libro de Actas del Cabildo del Cusco entre los años de 1813 a 1815 . Sesión del 13 de agosto de 1814 .

(58) CDIP, t. III, vol. VI, pág. 212. 
porque en términos históricos apelaba al retorno de una comunidad política antigua. Aspiraba a un orden en donde las prácticas de la desobediencia y el no acatamiento de la ley, lejos de representar un desprecio a la misma, garantizaban el no caer «en la desunión y contrariedad de principios en los poderes de la sociedad política, (cuando) es más perjudicial al hombre el estado de sociedad que el de naturaleza» (59). Así se comprende la importancia que para Angulo tenía el que se identificara la suya como una sublevación y no una sedición, calificando en este último caso su acto como una rebeldía permitida por las leyes naturales cuando las autoridades hacen un mal uso del poder (60).

La restitución de la justicia antigua abanderada por Angulo prendió mejor en la mentalidad de las corporaciones criollas cusqueñas que el discurso acerca de la representatividad defendida por los constitucionalistas. En su sermón del 5 de septiembre, el prebendado Francisco Carrascón, en nombre de la iglesia, celebró la recuperación de la libertad natural en el Cusco. Carrascón, en el curso de su alocuación, dijo que una nueva época se inauguraba con la irrupción de un gobierno aristocrático, que por fin ha suplido a un gobierno anticuado, monárquico y despótico, "porque nuestro imperio peruano se halla ya establecido en la santidad de la fe y en la lenidad de sus constumbres» (61). La rebelión de Angulo en defensa de la religión y la patria, implicó una ruptura tajante con la autoridad del rey. Exhumando elementos ideológicos tradicionales propios del escolasticismo y criticismo del siglo xvII, Angulo justificó el tiranicidio al ver reflejada en la Corona la personificación de la "torpe despiadada madrastra, a quien deben el ser corrompido racional, irreligioso, hipócrita» (62) en América. Á su modo de

(59) Ibid., pág. 212. Este enlace contradictorio entre tradición política antigua y fomento de la representación moderna durante el interregno liberal fue también una de las características de la llamada "Revolución de Mayo" que estalla en el Virreinato del Río de la Plata en 1810; ver Tulio HalPERIN Donghi, Tradición Política Española e Ideología Revolucionaria de Mayo. Buenos Aires, Eudeba, 1985.

(60) CDIP, t. III, vol. 6, pág. 212.

(61) CDIP, t. III, págs. 570-571.

(62) "Mensaje de la Ciudad del Cuzco al Virrey de Lima», CDIP, t. III, vol. 7, pág. 216.

R. I., 1996, n. 206 
ver, esa tiranía absolutista, lejos de haber sido abolida por las Cortes de Cádiz, se había profundizado favoreciendo los planes franceses de acabar con la religión. Angulo no ocultó su aversión a la modernización política que España y América experimentaban bajo el interregno liberal. Esta aversión fue claramente expresada en la respuesta que le mereció el ultimátum del general realista Juan Ramirez: «no debe ignorar los partidos que en la península se han fomentado entre constitucionales y realistas, y que hecha presa la metrópoli del primero que la ocupa, presenta la imagen más dolorosa de la ruina inevitable de nuestra madre la España" (63).

José Angulo, en nombre de la tradición política restituida, justificó el destierro de los partidos por un movimiento que se aprestara a restaurar el poder legítimo de la antigua comunidad local. Para Angulo, el Rey había muerto, tanto real como simbólicamente, por lo que era a la patria antigua a quien le correspondía asumir la soberanía popular. Fiel a sus propósitos, Angulo se encargó de difundir entre sus partidarios los rumores acerca de la muerte del Rey a manos de los franceses. En el proceso contra Pumacahua, éste confesó que había apoyado a Angulo porque «le hicieron creer que nuestro señor Soberano, el señor don Fernando VII había fallecido en la prisión o cautividad en que lo tuvieron los franceses y que en este caso se hallaba de defender la patria de cualquiera otra dominación" (64).

Angulo no sólo fue partidario de que el Cusco secundara las acciones que en el Sur ejecutaban los insurgentes de Buenos Aires, su proyecto también implicó recuperar las raíces de la identidad cusqueña. Angulo creó un mítico paraíso al que era dable volver para encontrar la antigua comunidad perdida: el Perú de los Incas (65). En ese paraíso andino era imposible «darnos ejemplo de la mentira y simulación, la hipocresía, la ingratitud, el adulterio y de cuanto crimen, que antes en el estado natural de los Incas se ignoraban, y los que se cono-

(63) CDIP, t. III, vol. 7, pág. 474

(64) CDIP, t. III, vol. 6 , pág. 310.

(65) Una recreación similar del legado iniciado también se produjo en varios de los mensajes de la Junta Revolucionaria de Buenos Aires, ver Tulio HALPERIN DoNGHI [59], págs. 103-107. 
cían se castigaban con pena corporal» (66). Un alto porcentaje del clero urbano se abocó a recuperar las sociabilidades antiguas en el Cusco, exaltando la figura de Angulo como nuevo mesías. En algunos sermones dominicales renació el discurso providencialista, gestándose un culto a la personalidad del líder cusqueño. Las tácticas de oposición y presión política usadas por el Cabildo contra Angulo y sus correligionarios no surtió ningún efecto. El llamado a respetar la Constitución y el orden fueron desoídos por insurgentes que, únicamente, estaban predispuestos a la restitución de la justicia y la libertad popular del pasado hasta sus últimas consecuencias. Al tornarse irreversible el proceso autonomista, a los constitucionalistas no les quedó otra alternativa que abandonar su táctica de oposición pasiva. En ese trance, ellos asistieron a la reunión extraordinaria de las máximas corporaciones, citadas por José y Vicente Angulo el 7 de septiembre en las salas del Ayuntamiento. Ese día, la Junta de Gobierno, la Diputación Provincial y el Cabildo acordaron redactar un oficio, dirigido a las autoridades políticas de Arequipa, en el que se recalcaba la tranquilidad del pueblo y que, inclusive, se contemplaba liberar a los oidores y demás europeos «con la lentitud y precauciones correspondientes al resentimiento y queja general contra ellos» (67). Seguidamente, se decidió el traslado de los oidores apresados a Paucartambo por razones de seguridad. Aunque en este episodio los cabildantes consiguieron que los documentos fueran redactados por los revolucionarios en un tono mesurado, las desconfianzas mutuas no disminuyeron.

A fines de septiembre una turba partidaria de Angulo asaltó la casa de un integrante de la Junta de Gobierno, el coronel Astete, por haberse opuesto a un plan tramado para ejecutar a los oidores. Astete logró huir de la ciudad y otro integrante de la misma, Juan Tomás Moscoso, presentó su renuncia. Angulo congregó a todas las autoridades locales en la sede del Cabildo, con el propósito de resolver el problema suscitado por las dos deserciones. Tomás Moscoso propuso que para salvaguardar la común felicidad, lo más conveniente sería que Angulo asumiera

(66) CDIP, t. III, vol. 6, pág. 217.

(67) CDIP, t. III, vol. 6, pág. 69. 
el cargo de gobernador, unificándose el mando político y militar. Los cabildantes apoyaron la iniciativa. Angulo terminó aceptando la propuesta de integrar la nueva junta al lado de Moscoso y Ferrándiz. El 5 de octubre Angulo juró el cargo de gobernador-presidente en nombre de la Constitución política de la monarquía española, pero aclarando que no acataría las órdenes del virrey en lo que no fuesen justas.

La toma del cargo por parte de Angulo en nombre de la Constitución fue recibido por el Cabildo como un verdadero triunfo, porque significaba encausar al gobierno insurgente dentro de la normativa vigente hasta antes de la revolución. Los constitucionalistas redactaron un oficio al virrey, resaltando la conducta del Ayuntamiento que "sin compromisos inevitables los dirigió siempre a buscar algún partido benéfico, y tuvo la satisfacción de que sus desvelos fuesen los inmediatos garantes de la quietud y sensación del desorden. En la elección de los gobernadores bajo del concepto de su sanidad y probidad influyó en lo posible...» (68).

El optimismo constitucionalista se cortó cuando las tropas leales al virrey, al mando del mariscal Picoaga, desde Arequipa, advirtieron a los insurgentes que depusieran su actitud o enfrentaran sus armas. En la sesión extraordinaria del 1 de noviembre celebrada en el Ayuntamiento, las tres corporaciones debían decidir sobre el modo de responder al ultimátum. El regidor Villacorta, a nombre del Cabildo, expuso que su voto era por la paz, pero dejó al Gobierno la decisión final, "pues ninguno de los señores del Congreso que votaron por la paz habían propuesto medios convenientes para realizarla» (69). La expedición militar hacia Arequipa comandada por Pumacahua y Vicente Angulo se tornó inevitable, sumándose ésta a las expediciones de Huamanga, Puno y La Paz emprendidas semanas antes (70). La suerte estaba echada para los cabildantes, que debieron refrendar los actos de José Angulo,

(68) ADC, Cabildo. Libro de Actas del Cabildo del Cusco, años de 1813 a 1815. Sesión del 11 de octubre de 1814.

(69) CDIP, t. III, vol. 6 , pág. 88.

(70) Para la historia de las expediciones, John LyNCH, The Spanish American Revolutions, 1808-1826. New York, W. W. Norton, 1973, págs. 168-169. FISHER [32], págs. 255-256. 
Juan Tomás Moscoso y Miguel Vargas, que interinamente sustituyó a Ferrándiz, a quien se había encomendado una misión política fuera de la ciudad.

La agonía del constitucionalismo se prolongó hasta la tercera elección del Cabildo Constitucional programada para el 18 de diciembre de 1814. A diferencia de todas las anteriores, en ésta las anomalías se presentaron desde la convocatoria. Faltando tres semanas para la elección, Ramírez de Arellano, que en las actas aparece como "procurador síndico", propuso la inconveniencia de reunir a las Juntas Parroquiales para la votación de electores atendiendo a las circunstancias que se vivían. Abandonando por primera vez su proclamado apego a la Constitución, Ramírez de Arellano opinó que lo más conveniente era convocar a los electores del año anterior (71). La idea fue recibida con entusiasmo por Angulo, quien la aprobó. La vuelta a la escena pública de este abogado, ahora ideológicamente al lado de Angulo, dejó al constitucionalismo sin su líder más importante. El Gobierno insurgente no sólo le otorgó la condición de coronel del ejército sino que le nombró Auditor de Guerra el 27 de diciembre de 1814. Ramírez de Arellano juró el cargo con una fórmula que omitía al Rey: «a nombre de la Patria que Dios prospere» (72).

Al sufragio del 18 de diciembre asistieron pocos electores. Muchos se negaron a votar y quienes salieron electos se negaron a jurar y asumir los cargos. Tras tres convocatorias fracasadas, Angulo junto con catorce electores obligaron en marzo de 1815 a José Mariano Ugarte a que aceptara ser el último alcalde constitucional del Cusco. Esta última elección de autoridades municipales selló el final del control constitucionalista tanto del Cabildo como del espacio urbano. El hecho coincidió con el principio del fin del proyecto revolucionario. En la mañana del 18 de marzo, la consternación invadió el Cusco al conocerse la derrota del ejército insurgente en Umachiri y la muerte de $\mathrm{Pu}$ macahua. Los cabildantes se reunieron sabiendo que las horas del gobierno estaban contadas. Ellos sólo atinaron a redactar un oficio solicitando la rendición a Angulo, atendiendo a que

(71) ADC, Cabildo. Libro de Actas del Cabildo del Cusco, años de 1813 a 1815. Sesión del 26 de noviembre de 1814 .

(72) CDIP, t. III, vol. 7, pág. 406. 
"este vecindario no ha tenido más parte en la actual sedición o revolución que haber obedecido siguiendo su costumbre» (73). El documento fue preparado de tal modo, que el Cabildo aparecía como la única corporación legalmente establecida dentro de la ciudad. Horas después, Angulo presentó su dimisión ante la corporación, aceptando transferir el poder al alcalde constitucional. El alcalde Mariano Ugarte convocó a los Cabildos civil y eclesiástico y la Diputación Provincial para informarles de la situación. Todas las corporaciones apoyaron su nominación como gobernador interino. De inmediato, redactaron el bando para hacerlo conocer al vecindario. Un rumor de último momento, que decía que las tropas habían tomado de sorpresa al general realista Ramírez, hizo que Angulo intentara retractarse de abandonar el gobierno. Su intención de permanecer en el poder no encontró eco en ninguna corporación ni en el vecindario (74). Los preparativos para ungir oficialmente al alcalde de primer voto como máxima autoridad cusqueña continuaron febrilmente.

El alcalde de primer voto fue declarado el 19 de marzo gobernador interino por todas las corporaciones reunidas, "principalmente porque estaban enterados de su fidelidad, amor y adhesión a la sagrada causa del Rey» (75). Todas las instituciones civiles y religiosas acordaron nombrar a sus representantes para la entrada del mariscal de campo Juan Ramírez y del ejército realista. Pero Ramírez no estaba dispuesto a ser recibido por ninguna autoridad criolla o mestiza. En vísperas de su ingreso a la ciudad, Ramírez se cuidó de que las corporaciones cusqueñas aceptaran a su emisario, el coronel Ramón González de Bernedo, como único gobernador intendente. Ugarte era humillado públicamente al ser desplazado del máximo cargo sin explicación alguna. Se trataba del primer paso hacia el retorno del ordenamiento realista. El Ayuntamiento fue horas después disuelto y el nuevo gobernador nombraba como alcalde provisional a Juan Tomás Moscoso. Los procesos sumarios abiertos no hicieron distinción entre constitucionalistas y revolucionarios. Pese a sus marcadas diferencias ideológicas, todos los sos-

(73) CDIP, t. III, vol. 6, págs. 138-139.

(74) CDIP, t. III, vol. 6, pág. 177.

(75) CDIP, t. III, vol. 6, pág. 143. 
pechosos de secundar a Angulo y el Cabildo fueron puestos en la misma condición de traidores a la Corona. Los oidores fueron restituidos en sus cargos. En los meses siguientes, una Audiencia revitalizaba con el poder absolutista se encargó de proscribir tanto la experiencia política representativa como el deseo de recuperar el pasado.

\section{ConCLuSIÓn}

Al estudiar las elecciones municipales del 29 de noviembre de 1812 celebradas en la capital mexicana, Antonio Annino llegó a la conclusión de que los criollos no sólo impugnaron por arrebatar a los peninsulares el control del Cabildo sino el del propio espacio urbano (76). Una situación similar se generó en el Cusco con ocasión de las elecciones del primer Cabildo constitucional del 14 de febrero de 1813. El vecindario cusqueño constituido por criollos, mestizos e indígenas se fragmentó, una parte apoyó al bando constitucional y otro segmento sostuvo la causa absolutista identificada con los peninsulares. Pese a los resultados electorales adversos de los absolutistas, y a diferencia del caso mexicano, ni las elecciones fueron suspendidas ni se impidió a los constitucionalistas criollos y mestizos tomar el poder local. De la contienda electoral se pasó a una guerra de palabras. Los cabildantes cusqueños, empeñados en su ofensiva para controlar el espacio urbano, se enfrentaron a las autoridades peninsulares congregadas alrededor de la Audiencia y la Intendencia. Esta lucha de poderes institucionales llevó a los constitucionalistas a proponer al Cabildo como la genuina corporación donde estaba representado el pueblo soberano. Según sus palabras, tanto los sufragios populares como el respaldo cotidiano del pueblo lo avalaban. Los oidores replicaron contra esos argumentos que los constitucionalistas se apoyaban en un sector de la plebe insolente y desleal. Para los oidores, la única autoridad suprema en el Cusco era la nombrada directamente por el virrey Abascal,

(76) Antonio ANNINO, "Prácticas criollas y liberalismo en la crisis del espacio urbano colonial. El 29 de noviembre de 1812 en la ciudad de México», Secuencia, n.॰ 24, 1992, pág. 124.

R. I., 1996, n.॰ 206 
por lo cual el Cabildo sólo debía ocuparse de tareas administrativas previamente acordadas con la Audiencia.

Si dicho conflicto se hubiera desenvuelto siguiendo exclusivamente los acontecimientos en la metrópoli, y, en especial, por lo ocurrido con la Constitución después de la restauración de Fernando VII, es posible que los constitucionalistas hubiesen fracasado en alcanzar el control del espacio urbano. Pero la guerra de palabras se cortó el 3 de agosto de 1814, fecha que marcó el inicio de la llamada revolución del Cusco liderada por José Angulo. Angulo, lejos de terciar en la polémica sobre la soberanía local, rechazó tanto las argumentaciones de los absolutistas como de los constitucionalistas. Deploró la formación de ambos partidos o facciones políticas como el resultado directo de la progresiva pérdida de la libertad criolla iniciada por España a lo largo del siglo xviII. Amparándose en las leyes naturales, justificó el tiranicidio y el apoyo del Cusco a los insurgentes de Buenos Aires con el objeto de restaurar la libertad antigua. No veía en el Cabildo ninguna representatividad de la autoridad popular. La paradoja de su empeño por restaurar las libertades antiguas fue que finalmente se vio obligado a juramentar como máxima autoridad cusqueña en nombre de la Constitución de 1812, autorizando la celebración de nuevas elecciones municipales. La legitimidad política propiciada por Angulo pasó por una contradictoria asociación entre su revolución, las elecciones y el constitucionalismo que a la postre le significó el fracaso en su intención de consolidar un poder que aspiraba a sobrepasar el mero dominio del espacio urbano cusqueño.

The political events of Spain in 1808 introduce unprecedented political practices in Hispanic America. For example, the Audience of Cusco held periodical elections of representatives to the Spanish Cortes, and to Provincial and Municipal Assemblies. The struggle for power between the town council, dominated by constitutionalists, and the Audience, considered by the absolutists as the supreme instance of power, was interrupted by the outbreak of revolution led by José Angulo on 3rd August 1814. Research in Peruvian and Spanish archives shows that this introduced an ideological discourse and politcal aims which differed from those of both absolutists and constitutionalists, and meant that the elections lost their initial significance. 